\title{
Evaluating Flight Crew Operator Manual Documentation
}

\author{
Lance Sherry \\ Honeywell - ATS \\ PO Box 21111 \\ Phoenix, AZ, 85027 \\ lance.sherry@cas.honeywell.com
}

\author{
Michael Feary \\ MS 262-4 \\ Ames Research Center \\ Moffett Field, CA 94035 \\ mfeary@mail.arc.nasa.gov
}

\begin{abstract}
Aviation and cognitive science researchers have identified situations in which the pilot's expectations for the behavior of the avionics are not matched by the actual behavior of the avionics. Researchers have attributed these "automation surprises" to the complexity of the avionics mode logic, the absence of complete training, limitations in cockpit displays, and ad-hoc conceptual models of the avionics.

Complete canonical rule-based descriptions of the behavior of the autopilot provide the basis for understanding the perceived complexity of the autopilots, the differences between the pilot's and autopilot's conceptual models, and the limitations in training materials and cockpit displays.

This paper compares the behavior of the autopilot Vertical Speed/Flight Path Angle (VS-FPA) mode as described in the Flight Crew Operators Manual (FCOM) and the actual behavior of the VS-FPA mode defined in the autopilot software. This example demonstrates the use of the Operational Procedure Model (OPM) as a method for using the requirements specification for the design of the software logic as information requirements for training.
\end{abstract}

\section{INTRODUCTION}

The FAA report, Interfaces Between Flightcrews and Modern Flightdeck Systems [4], identifies issues associated with pilot's management of automation (pages 33 to 41). The report catalogues gaps in pilot's understanding of the capabilities, the limitations, the modes, and the operating principles and techniques of modern cockpit automation. The report describes "automation surprises" where the automation behaved in ways the flight crew did not expect. As an example, the report cites Wiener's [12] studies where frequently asked questions of the of the avionics behavior: "What is it doing now?" "Why is it doing that?" and "What's it going to do next?" The report also describes differing pilot decisions about the appropriate levels of automation and the different assumptions made by manufacturers in designing these systems.
These issues with the cooperation between pilots and avionics are demonstrated by airline policies that prohibit use of certain parts of the automation, and by pilots who choose not to use parts of the automation [3], [6].

Researchers have cited the limits of human cognition, operational complexity, ad-hoc conceptual models of the avionics, and limitations in the content and form of cockpit displays and training materials as factors contributing to "automation surprise" events. Cockpit displays and training material are the primary source of the structure and content of the pilots' mental model of the operation of the avionics. The constructs, grammars, and visual representation of this information are critical to the formulation of accurate, rapid, complex, flexible, and meaningful pilot mental models.

\section{Content and Form of Training Material}

Airframers and airline operators have traditionally avoided the conceptual model issue by only providing training for the basic operating techniques of the automation. Pilots are given the knowledge to perform certain "critical" tasks with the avionics and then required to develop their own mental model through operational "line" flying and the operator manuals provided by the manufacturer and/or airline.

The official source of information on the operation of the avionics is the Flight Crew Operators Manual (FCOM). The FCOM is written and published by the airframe manufacturer. Airlines typically republish adapted versions of the airframers FCOM with additional airline specific information, policies and procedures.

The FCOM is required to include a wide range of information:

description of the cockpit panels and displays procedures (normal operation) for each phase of flight procedures (abnormal and emergency operation) for each phase of flight

checklists

description of the modes and the behavior of the modes of the aircraft systems

description of the architecture of the aircraft systems 
An FCOM is typically developed during flight-test and certification of an aircraft or new equipment. The developers of the FCOM, with training and publishing backgrounds, work with specifications of the system furnished by the engineers and with expert pilots. Frequently sections of the FCOM can be derived from earlier generations or manuals from other airplanes [7]. Following iteration and the review and certification processes, the final version of the manuals is made available for publication and distribution. Updates to the manuals are provided to pilots with additional information about new avionics loads and improved sections.

The authors of the FCOM are faced with a number of human-factors issues in capturing and presenting the information in readable, understandable formats. In addition, the FCOM is required to serve as both a means for educating the beginner as well as a reference source for the expert operator.

\section{CANONICAL RULE BASED DESCRIPTIONS OF THE AVIONICS}

The specification of avionics systems include numerous rules made by the designers of the system about how the aircraft should "behave" in certain situations. This decision logic can be organized as a canonical rule-based description, which can serve multiple purposes, including the generation of training material. Sherry [8] introduced a canonical rule-based, situation-action pair representation to describe the behavior of avionics:

Intention $=f($ situations, actions $)$

Where: $\quad$ situations $=>$ conditions when an action will be taken

actions $=>$ commands, changes to displays or symbolic data structures

The situation part of the rule represents the overall operational condition that the aircraft is in. The situation is defined based on parameters that include: aircraft altitude, aircraft speeds, the location of the aircraft in the flightplan, the configuration of the cockpit, and state of the on-board equipment and sensors.

Given a situation, the avionics executes an associated set of actions. Actions include: pitch/thrust/roll commands, modification to the flightplan, and new speed/altitude/vertical speed target.

This canonical representation also includes information on the intention of the action. This information is useful in abstracting complex, detailed situation-action pairs with an operational objective.

An example situation-action rule for an autopilot Vertical Speed mode is illustrated in Figure 1. As is evident in this example, canonical situation-action pair representations of the behavior of autopilots are dominated by the descriptions of the situation. In the actual avionics software, up to $80 \%$ of the behavior of the avionics is based on conditional IF-THEN-ELSE constructs and logical equations. The remaining $20 \%$ of the behavior of the avionics is associated with repetitive tasks (such as closed-loop control of pitch), optimization (such as ECON speeds), symbolic manipulation of data (such as the Flightplan and cockpit displays).

\begin{tabular}{|ll} 
Intention: & $\begin{array}{l}\text { Honor pilot request to maintain pilot entered } \\
\text { Vertical Speed to pilot entered Altitude at pilo } \\
\text { entered speed. }\end{array}$ \\
Situation: & $\begin{array}{l}\text { Pilot selects the Pitch Wheel above 400ft RA } \\
\text { and below 1500ft AGL when the Autopilot is } \\
\text { engaged in Takeoff. Go Around, Level Change, } \\
\text { Altitude Hold, or Altitude Capture }\end{array}$
\end{tabular}

This situation shall occur when all of the following conditions are satisfied:

a) Aircraft Altitude is between 400ft Radio Altitude and $1500 \mathrm{ft}$ Baro Altitude

b) Aircraft speed is between Vmin +5 knots and Vmax + 5 knots

Comment: Aircraft speed has not violated the speed envelope.

c) Predicted Aircraft speed in 10 seconds is between Vmin +5 knots and Vmax +5 knots

d) Aircraft is not within the Altitude Capture or Hold

e) $\quad$ Autopilot remains engaged

f) PROF mode remains not engaged

g) GCP Pitch Wheel is rotated

h) Radio Altitude is valid

) Autopilot Pitch Mode is Takeoff, Go Around, Level Change, VS/FPA, Altitude Capture, Altitude Hold, Glideslope, Nose Lowering, or Flare.

Action:

Closed-loop control of vertical speed using pitch

Closed-loop control of speed using throttles

Flight Mode Annunciation "THRUST | VS"

Example situation-action rule for autopilot vertical speed mode.

Figure 1

Complete and Approximate Descriptions of Behavior A canonical situation-action pair description of the behavior of a system is considered to be complete when all the possible situations that can occur in a mission are included in the description. 


\begin{tabular}{|c|c|c|c|c|c|}
\hline \multirow{2}{*}{$\begin{array}{l}\text { Operational } \\
\text { Procedures } \\
\end{array}$} & \multicolumn{5}{|c|}{ Transition to VSFPA } \\
\hline & & \begin{tabular}{l}
\multicolumn{1}{c}{5} \\
Vertical Speed \\
Wheel on the FCP \\
is Selected when \\
Autopilot or Flight \\
Director is \\
Engaged in an \\
Altitude Capture \\
when radio \\
Altitude is Invalid \\
and the Change in \\
VS places the \\
Aircraft Outside \\
of the Capture \\
Region of the \\
Selected Altitude
\end{tabular} & $\begin{array}{c}7 \\
\text { Autopilot or Flight } \\
\text { Director are } \\
\text { Engaged in Takeoff, } \\
\text { Go Around, or } \\
\text { Windshear Pitch } \\
\text { Modes and the } \\
\text { Aircraft is Greater } \\
\text { than 400ft AGL with } \\
\text { VS is Greater than } \\
\text { +/-300 fpm. }\end{array}$ & $\begin{array}{c}.14 \\
\text { Aircraft speed } \\
\text { violates Vmin } \\
-5 \text { knots }\end{array}$ & $\begin{array}{c}15 \\
\text { Aircraft Speed } \\
\text { Exceeds Vmo/Mmo } \\
+5 \text { knots. }\end{array}$ \\
\hline $\begin{array}{l}\text { Scenario } \\
\text { Inputs }\end{array}$ & States & & & & \\
\hline \multirow[t]{2}{*}{ V/S on GCP } & Is selected & Is selected & & & \\
\hline & Is not selected & & & & \\
\hline \multirow{2}{*}{$\begin{array}{l}\text { Altitude } \\
\text { Capture revert } \\
\text { to VS-FPA }\end{array}$} & Invoked & Invoked & & & \\
\hline & Not Invoked & & & & \\
\hline \multirow{2}{*}{$\begin{array}{l}\text { Radio Altitude } \\
\text { Estimate }\end{array}$} & Valid & & Valid & & \\
\hline & Not Valid & Not Valid & & & \\
\hline \multirow{2}{*}{$\begin{array}{l}\text { Radio Altitude } \\
\text { Estimate }\end{array}$} & $>400 \mathrm{ft}$ & & $>400 \mathrm{ft}$ & & \\
\hline & $<400 \mathrm{ft}$ & & & & \\
\hline \multirow[t]{5}{*}{ Pitch mode } & Takeoff & Takeoff & Takeoff & & \\
\hline & Go-Around & Go-Around & Go-Around & & \\
\hline & Level Change & Level Change & Level Change & Level Change & Level Change \\
\hline & Windshear & & & & \\
\hline & Others & Others & Others & & \\
\hline \multirow[t]{2}{*}{ Aircraft Speed } & $<\mathrm{Vmin}-5$ knots & & & $<$ Vmin -5 knots & \\
\hline & $>V \min -5$ knots & & & & \\
\hline \multirow[t]{2}{*}{ Aircraft Speed } & $<\mathrm{Vmax}+5$ knots & & & & \\
\hline & $>V \max +5$ knots & & & & $>\mathrm{Vmax}+5$ knots \\
\hline \multicolumn{6}{|l|}{$\begin{array}{l}\text { Behavior } \\
\text { Outputs }\end{array}$} \\
\hline \multirow[t]{2}{*}{ VSFPA Pitch } & Transition & Transition & Transition & Transition & Transition \\
\hline & No Transition & & & & \\
\hline
\end{tabular}

\section{Example Portion of Operational Procedure Table for Autopilot Vertical Speed Mode.}

Table 1

An illustration of a method for formally validating completeness is shown in the Operational Procedure Table (OPT) example, Table 1. Mathematical models underlying the model verify that for each situation there is one and only one corresponding action.

The possible situations in a mission are defined as every possible combination of values held by the parameters that have been identified to be relevant to the behavior. In the example in Table 1, aircraft radio altitude validity and aircraft relation to $400 \mathrm{ft}, \mathrm{V} / \mathrm{S}$ wheel selection on the Glareshield Control Panel (GCP), invocation of altitude capture aircraft speed relative to $\mathrm{V}_{\max }$ and $\mathrm{V}_{\min }$ are examples of parameters and their values.

A canonical situation-action pair description of the behavior of a system is considered approximate when either: (i) all the relevant parameters are not included (i.e. descriptions of situations are simplified), or (ii) all the possible values of these parameters are not covered by a situation (i.e. situations are missing).

\section{RULE-BASED DESCRIPTION OF THE VERTICAL SPEED PITCH MODES OF A MODERN AUTOPILOT}


Autopilots in modern "glass cockpits" include modes of operation that coordinate control of the pitch and thrust axes. Level Change, Altitude Capture, Altitude Hold, and Vertical Speed/Flight Path Angle pitch modes are known as the Cruise Pitch Modes. These pitch modes are available when the aircraft is greater than $400 \mathrm{ft}$ AGL when the Radio Altitude is valid and Takeoff, Go Around, Windshear pitch modes are not engaged (or at any altitude when Radio Altitude is not valid and Takeoff, Go Around, Windshear pitch modes are not engaged).

A cruise pitch mode may be engaged, disengaged or inhibited from engaging. Hutchins [6] has examined pilot difficulty in determining which criteria have been satisfied.

A total of 252 mission situations affect the cruise pitch modes. These 25 scenarios are based on 62 parameters. The engagement/ disengagement situations and the number of parameters used in the rules for each cruise pitch mode are summarized in Table 2. The rules for engagement/ disengagement of Level Change are the simplest. The rules for the engagement/disengagement of Altitude Hold are the most complex.

\begin{tabular}{|l|c|c|}
\hline \multicolumn{1}{|c|}{ Pitch Cruise Mode } & $\begin{array}{c}\text { Situations for } \\
\text { Engagement/ } \\
\text { Disengagement of } \\
\text { Pitch Mode }\end{array}$ & Parameters \\
\hline To Level Change & $23 / 9$ & 15 \\
\hline To Altitude Capture & $50 / 30$ & 21 \\
\hline To Altitude Hold \\
To Vertical Speed/ \\
Flight Path Angle
\end{tabular}

Summary of Rules in Autopilot VS/FPA mode. Table 2

A typical description in the FCOM of the operation of the Vertical Speed Mode for a modern autopilot is illustrated in the left side "boxed section of Figure 2.

\section{Mixed Content Descriptions}

The description in the FCOM includes a lot of different types of information. The different types of information are not separated. They are intertwined in a narrative description. The different types of information are summarized below:

pilot operation of the Mode Control Panel (MCP) the Flight Mode annunciation

behavior of the autothrottle

behavior of the Vertical Speed Mode

\section{Buried Rule-based Description}

The FCOM description of behavior of the Vertical Speed Mode is included in narrative form. The conditional rules for operation, underlined in Figure 2, are not highlighted and difficult to separate into rules.

Given the incomplete nature of the training materials and the type of training that is currently given, currently pilots receive insufficient knowledge for the development of complete and accurate mental models of the avionics.

\section{Approximate Descriptions}

The current FCOM description of the behavior of the Vertical Speed Mode is an approximate and incomplete description. The FCOM includes 12 of the 16 situations in the actual software for engagement of the mode, and 4 of the 12 situations in the actual software in which the selection of the mode is inhibited or in which the mode is automatically disengaged.

The FCOM description of behavior is based on 9 parameters. The description of behavior of the avionics software is based on 12 parameters. It is easy to see that it is extremely difficult for a pilot to develop an accurate mental model of the avionics without a complete and accurate description of the behavior of the avionics.

Viewing these parameters, it is evident that the operational complexity in the behavior of the autopilot is necessary given the constraints in aviation. The behavior of the autopilot is determined by parameters that represent the environment (terrain and weather), aircraft dynamics, pilot delegation of authority to the automation, operational procedures, and technologies that enhance capacity and safety (e.g. glideslope). Therefore, reduction in operational complexity would be possible only with a reduction in functionality.

\section{CONCLUSIONS}

A reduction in perceived complexity may be achieved by reducing or eliminating differences between pilots' operational models and the operational models encoded in the autopilot. Complete rule-based descriptions of the behavior of the autopilot provide the basis for understanding the perceived complexity of the autopilots, differences between pilot and autopilot conceptual models, and the limitations in training materials and cockpit displays.

The most powerful means pilots have of learning the behavior of the autopilot is through observation. When the cockpit displays do not annunciate a complete canonical intention-situation-action behavior of the autopilot, the pilot is left to create approximate models of the autopilot's behavior. Due to the nature of the logical, decision-making of situation assessment, it is very difficult to generalize behavior in a meaningful way. Small changes in the value of a parameter used in situation assessment can result in significantly different actions. Feary, et. al. [5] have demonstrated the value of this approach. 
To support pilots learning complete canonical descriptions of the behavior, Sherry \& Polson [10] propose using interactive, computer-based training to incrementally increase the pilots' mental model. Modern 
Pitch Wheel: When rotated slowly, results in $100 \mathrm{fpm}$ or .1 degree change per detent. In level flight with FD and or AP/FD on, initial wheel rotation selects V/S mode in 100s of fpm or FPA in degrees in the direction of wheel rotation. In a climb or descent greater than $300 \mathrm{fpm}$, the mode and display are initialized to the current V/S or FPA when either the AP or FD are engaged. Once engaged, the displayed value is always the selected value. Selection of V/S-FPA mode disengages PROF, speed-on-pitch (PITCH in the FMA speed window), altitude hold and glideslope modes if LAND is not annunciated. Autothrottles revert to speed control (THRUST in FMA window). Reselecting PROF resumes FMS descent profile operation at the vertical speed as a FMS edit.

Rotation of the pitch wheel causes the aircraft to depart the FCP selected altitude in vertical speed or flight path angle mode WITHOUT A FLOOR OR CEILING ALTITUDE. Rotation of the pitch wheel enables the pilot to exit altitude capture for 2 seconds where upon if altitude capture conditions are satisfied, the aircraft reenters altitude capture. Otherwise the vertical speed remains selected. This feature is operable in all modes except dual flight directors control below $1500 \mathrm{ft}$, SINGLE or DUAL LAND and below 400ft RA in the pitch autopilot or flight director takeoff or go around modes.

\author{
Engagement Scenarios \\ 7,8 , and 9 \\ Engagement Scenarios \\ | Engagement Scenarios \\ $1,2,3$ \\ | Engagement Scenario \\ $4,5,6$ \\ Inhibit Scenarios \\ $17,18,21,22,23$ \\ Missing: \\ Engagement Scenarios 13-16 \\ Inhibit Scenarios 19, 20, 24-28
}

Pitch Wheel: When rotated slowly, results in $100 \mathrm{fpm}$ or .1 degree change per detent. In level flight with FD and or AP/FD on, initial wheel rotation selects V/S mode in $100 \mathrm{~s}$ of fpm or FPA in degrees in the direction of wheel rotation. In a climb or descent greater than $300 \mathrm{fpm}$, the mode and display are initialized to the current V/S or FPA when either the AP or FD are engaged. Once engaged, the displayed value is always the selected value. Selection of V/S-FPA mode disengages PROF, speed-on-pitch (PITCH in the FMA speed window), altitude hold and glideslope modes if LAND is not annunciated. Autothrottles revert to speed control (THRUST in FMA window). Reselecting PROF resumes FMS descent profile operation at the selected vertical speed as a FMS edit.

Rotation of the pitch wheel causes the aircraft to depart the FCP selected altitude in vertical speed or flight path angle mode WITHOUT A FLOOR OR CEILING ALTITUDE. Rotation of the pitch wheel enables the pilot to exit altitude capture for 2 seconds where upon if altitude capture conditions are satisfied, the aircraft reenters altitude capture. Otherwise the vertical speed remains selected. This feature is operable in all modes except dual flight directors control below $1500 \mathrm{ft}$, SINGLE or DUAL LAND and below 400ft RA in the pitch autopilot or flight director takeoff or go around modes.

\author{
| \\ | \\ | How the VS-FPAdisplay works \\ | Pitch Mode disengaged \\ |Thrust axis operation \\ | PROFMode VS Targets
}

Example FCOM for Autopilot Vertical Speed Mode. Underlined text provides approximate model description of the behavior of this mode.

Figure 2 
theories of complex skill acquisition [1] suggest that it is reasonable to assume that pilots can learn to anticipate and monitor the behavior of large rule-based systems. Typical users of PC spreadsheets make use of approximately 300 rules. Grand master chess players (those who have studied chess intensely for at least 10 years) have mental-models that include 10,000 to 100 , 000 rules of behavior [2]. There are similarities between pilot's training, both formal and on-the-job, and the types of training which office automation users and chess players perform that strengthens this assertion.

\section{Acknowledgments}

This research was supported by the National Aeronautics and Space Administration under contract NAS1-20219 to Honeywell (COTR: Everett Palmer). The authors thank Joe Juarez, Dan McCrobie, Steve Quarry, Arturo Suarez, (Honeywell), Peter Polson (UC), Phil Wolfe (ASU), and Charlie Hynes (NASA) for several technical contributions. Also Joe Jackson (Honeywell), Joe Conley and Mike Lewis (NASA) for support of this research

\section{REFERENCES}

[1] Anderson, J. Rules of the Mind. Hillsdale, NJ: Lawrence Erlbaum \& Associates, 1993.

[2]Chase, W., \& Simon, H., "A Perception in Chess", Cognitive Psychology, 1973, 4, pp. 55-81.

[3]Eldredge, D., Mangold, S., and Dodd, R. S. "A Review and Discussion of Flight Management System Incidents Reported to the Aviation Safety Reporting System" Final Report no. DOT/FAA/RD-92/2. Washington DC: Battelle, U.S. Department of Transportation, 1992.

[4] FAA, Federal Aviation Administration Human Factors Report on the Interfaces between Flight Crews and Modern Flight Deck Systems. 1996

[5]Feary, M., McCrobie, D., Sherry, L., Alkin, M., Polson, P., Palmer, E., \& McQuinn, N. "Aiding Vertical Guidance Understanding," International Conference on Human-Computer Interaction in Aeronautics, May 1998, pp. 165-170

[6]E. Hutchins Integrated Mode Management Interface, NASA Ames Research Center, Mountain View, CA. 1996

[7] Novick, D. G., and Tazi, S. "Flight Crew Operating Manuals as Dialogue: The Act-Function-Phase Model," International Conference on Human-Computer Interaction in Aeronautics, May 1998, pp. 179-184

[8]L. Sherry, "A Formalism for the Specification of Operationally Embedded Reactive Systems," Proceedings
International Council on System Engineering, St. Louis, MO. 1995

[9] Sherry, L., Youssefi, D., \& Hynes, C. H. A formalism for the specification of operationally embedded reactive systems. (Honeywell publication no. C69-5350-001). Phoenix, AZ. 1995

[10] Sherry, L., \& Polson, P. "Implications of SituationAction Rule Descriptions of Avionics Behavior," International Conference on Human-Computer Interaction in Aeronautics, May 1998, pp. 213-219.

[11] Vakil, S., Hansmann, J., Midkiff, A., and Vanek T., "Feedback Mechanisms to Improve Mode Awareness in Advanced Autoflight Systems. In Proceedings of the Eighth International Aviation Psychology Symposium, Columbus, OH:Ohio State University, 1995a.

[12] E. Wiener, Human Factors of Advanced Technology ("Glass Cockpit") Transport Aircraft. NASA CR177528, 1989. 
The relationship between the jurisdiction of pilots' models of the operation of the mission and the jurisdiction of models encoded into the autopilot is a key determinant of pilot-avionics cooperation. When the conceptual models have no overlap there is no chance for "operator-automation disagreement." When the pilot's and the autopilot's operational models overlap, such as speed protection, differences in these models can result in "operator-automation disagreements." When these disagreements are not annunciated, "operator-automation surprises" occur. 